\title{
O TEATRO DE DARIO FO: DESNUDANDO FO EM PICASSO NU
}

\author{
Sergio Nunes Melo \\ Coordenador e Professor do Curso de Artes Cênicas (UFSC) \\ Formado pela Scuola d'Arte Drammatica Paolo Grassi (Itália) \\ Doutorado pela University of Toronto (Canadá) \\ Ator, Dramaturgo e Roteirista \\ E-mail: sergio.nmelo@gmail.com
}

Este artigo se baseia nos relatos do próprio Dario Fo e nas pesquisas de Antonio Scuderi (2000), Tom Behan (2000) e Tony Mitchell (2014) para demonstrar o caráter improvisacional, popular e político da obra dramatúrgica de Fo. Para tal fim, o artigo discute o teatro de Fo através da exposição e análise de trechos de um dos trabalhos mais recentes do autor: a palestra-espetáculo Picasso Nu (Picasso Desnudo - 2012). Nesse espetáculo, Fo e sua esposa, Franca Rame, ambos com mais de oitenta anos de idade, improvisaram a partir de um roteiro pontuado por projeções de imagens de Picasso, seus quadros, seus interlocutores e suas histórias. $\mathrm{O}$ artigo também demonstra como a personagem histórica Pablo Picasso e seus interlocutores servem de pretexto para que Fo desnude o seu próprio fazer artístico.

Dario Fo. Teatro Físico. Interdiscursividade. Picasso. Teatro Político
This article draws upon both Dario Fo's own accountings as well as the scholarship of Antonio Scuderi (2000), Tom Behan (2000) and Tony Mitchell (2014) in order to demonstrate the improvisational, popular and political character of Fo's playwriting. To this end, the article discusses Fo's theatre though the exposition and analysis of bits of one of the author's most recent works: the lecture-spectacle Picasso Desnudo (Naked Picasso - 2012). In this show Fo and his wife, Franca Rame, both aging over eighty, improvised according to a script cued by the projection of images of Picasso, his paintings, his interlocutors and their stories. The article also demonstrates how the historical character Pablo Picasso and his interlocutors are employed as a pretext so that Fo undresses his own artistic doing.

Keywords

Dario Fo. Physical Theatre. Interdiscursivity. Picasso. Political Theatre 
[...] O estudo da arte verbal pode e deve superar o divórcio entre uma abordagem abstrata do "formal" e uma abordagem igualmente abstrata do "ideológico". A forma e o conteúdo no discurso são um só, desde que se tenha compreendido que o discurso verbal é um fenômeno social - social através de todo o seu espectro e em cada um de seus fatores, desde a imagem do som até os alcances mais longínguos do significado abstrato. (Bakhtin, 1981, p. 269) ${ }^{1}$

\section{Redefinindo}

O Conceito De Literatura Dramática

Logo de saída, a respeito do teatro de Dario Fo (pronuncia-se Dário Fó), é necessário que se deixe claro que, embora tenha honrado seu criador com um Prêmio Nobel de Literatura em 1997, não se trata de uma arte textocêntrica, na medida em que é um produto da tradição oral. Seu registro em forma escrita, portanto, é uma partitura desde o corpo e para o corpo. Isso não quer dizer absolutamente que a palavra não seja muito importante em suas peças. Só não é a parte mais importante, como, por exemplo, no teatro de Pirandello, para citar outro dramaturgo laureado com tal magnitude, cuja peça mais famosa é justamente uma espécie de tese: Assim é (se lhe parece).

Com relação ao texto de Pirandello, montagens com visões pessoais, trans-históricas, historicistas, realistas, simbolistas, localizadas, deslocadas e muitas outras abordagens poderão se suceder, com ou sem cortes, com ou sem adaptações; mas, hierarquicamente, o texto comandará fortemente a encenação dada a especificidade de sua mensagem filosófica. Do contrário, não há sentido nessas concretizações. Por outro lado, as peças de Fo, que apresentam, como alvos de crítica, situações específicas da Itália, estão necessariamente condicionadas a serem encenadas por outros diretores e atores através de deslocamentos - de lugares, de referências, de citações, de objetos de paródia, de alvos de sátira e de línguas. Por essas razões, as peças de Fo suscitam polêmicas, estando sujeitas a processos judiciais por difamação, blasfêmia, subversão e obscenidade.

As peças de Fo implicam um confronto corpo a corpo, face a face e uma interação física e genuinamente ativista em prol da classe trabalhadora, das mulheres e dos injustiçados em geral - inegáveis forças motrizes desse teatro desde, pelo menos, 1968, ano considerado um divisor de águas na produção artística de Fo, que, então, troca o teatro burguês pelo teatro ativista. Além de se caracterizarem por essa linguagem deliberadamente ofensiva, os textos são modificados de acordo com as reações do público (Behan, 2000). Desse modo, ao teatro de Fo, cabe a insatisfatória, porém necessária, classificação de teatro físico.

A afirmação de que a obra dramatúrgica de Fo é uma modalidade de teatro físico ressalta que forma e conteúdo andam de mãos dadas consciente e materialmente em seu teatro, constituindo um discurso artístico paradoxal não somente em seus temas e em seu estilo mas também em seu modus operandi. Ao receber a premiação mais celebrada do mundo, "Fo teve êxito em elevar o status da tradição oral ao nível do prestígio literário de modo bem real e ajudou a redefinir o conceito de 'literatura' na medida que essa deve compreender a tradição oral e a atuação" (Scuderi, 2000, p. 37).

\footnotetext{
1 Todas as traduções de citações consultadas em línguas estrangeiras são minhas bem como as transcrições de trechos do espetáculo.
} 
0 Teatro Como Instrumento De Politização

O reconhecimento da ampliação do conceito de 'literatura' a partir do gesto simbólico da Academia Sueca é fundamental porque, para Fo, o teatro é uma prática social não só porque é uma modalidade de entretenimento que requer cuidado rigoroso através de engajamento físico extracotidiano mas também porque é uma poderosa manifestação de resistência a qualquer forma de opressão, inclusive e principalmente à opressão intelectual. Conforme atesta a secretaria do Prêmio Nobel, Fo recebeu tal distinção "por copiar os comediantes da Idade Média na medida em que tripudia do poder e apoia a dignidade dos oprimidos" (1997). Assim, o teatro de Fo põe em xeque a homologia estabelecida, desde a Antiguidade, entre elite e obra de arte maior, uma construção da cultura oficial. Por isso, em sua dramaturgia,

[...] um tema primordial é que a classe dominante conseguiu se apropriar daquilo que queria da cultura popular, privou-a de sua dignidade e de sua validade e a reapresentou como inferior. Como parte desse processo, a classe dominante recontou a história, apresentando-a de modo a servir seu propósito. O teatro de Fo trabalha no sentido de retificar essa bastardização da história e essa deturpação da cultura popular através da apresentação da história por um prisma subalterno e para lhes restituir o que a cultura oficial Ihes retirou. (Scuderi, 2000, p. 28)

Coerentemente, Fo tem sido uma espécie de Robin Hood do teatro, contando histórias com o objetivo de recontar a história e devolver a dignidade àqueles de quem ela foi estirpada, pois "[c]om uma mistura de riso e gravidade, ele abre nossos olhos para os abusos e as injustiças e também para uma perspectiva histórica mais ampla com a qual exergá-los" (SECRETARIA PERMANENTE DO PRÊMIO NOBEL, 1997). Note-se bem que não existe, na dialética de Fo, um foco na política partidária, que se resolve nas instâncias governamentais. Trata-se aqui, na verdade, do cultivo da transgressão como atitude política capaz de transformar a sociedade. Para isso, uma de suas estratégias mais transgressivas é o uso corrosivo do humor, que ele explicitamente rouba da tradição.

\section{Saqueando A Tradição}

Fo tem incorporado à sua obra uma série de formas artísticas, com frequência, injustamente consideradas "menores" porque são populares: a palhaçaria, a farsa, a acrobacia, o teatro de bonecos, o teatro de variedades, o cinema mudo bem como, de modo especial, a Commedia dell'Arte e a contação de histórias. (Scuderi, 2000, p. 27) A contaminação de Fo pela tradição oral está no sangue, tanto em sua família quanto na daquela que foi sua parceira por mais de seis décadas de casamento e de trabalho, Franca Rame (1929-2013), cuja ancestralidade teatral remonta a uma dinastia ininterrupta iniciada no século XVI. Por isso mesmo, Rame era frequentemente chamada por Fo para entrar em cena com o epíteto de "depositária do teatro italiano à antiga." No caso de Fo, seu avô materno era um vendedor ambulante de legumes, conhecido por uma verve apurada, que contava histórias e fazia comentários sagazes, utilizando-se, por exemplo, de abobrinhas e congêneres para se referir a partes do corpo de algum dos personagens de suas narrativas, atraindo, assim, 
potenciais freguezes de suas mercadorias.

Natural da Lombardia, província da Itália setentrional, Fo teve à sua disposição, muitos exemplos de fabulatori (fabuladores/contadores de histórias), os quais, como seu avô, eram herdeiros de uma tradição oral com a qual ele tem construído o que ele próprio considera a base de sua dramaturgia: as giullarate. O termo giullarata, no singular, deriva de giullare, palavra sem uma tradução precisa em português e que se refere a um personagem que apresenta, simultaneamente, o caráter de comediante, palhaço e bobo da corte. As giullarate são espetáculos solo em que o autor -ator-diretor representa em dialetos, ${ }^{2}$ línguas pitorescas que evocam culturas regionais, sonoridades particulares e tipos emblemáticos da dinâmica de poder. A respeito dessa influência, em seu discurso de aceitação do Prêmio Nobel, Fo declara, que:

Ruzzante, o verdadeiro pai da Commedia dell'Arte, também construiu uma linguagem toda sua, uma língua de e para o teatro, baseada numa série de línguas: os dialetos do Vale do Pó, expressões em latim, espanhol e até alemão, todas misturadas com sons onomatopaicos de sua própria invenção. Foi com ele, com Beolco Ruzzante, que aprendi a me libertar da minha escrita literária convencional e a me expressar com palavras que se podem mastigar, com sons incomuns, com várias técnicas de ritmo e respiração, inclusive com o som balbuciante e nonsense do grammelot. (Fo, 1997)

Diferentemente da Commedia dell'Arte, porém, no teatro de Fo, o roteiro não é somente uma estrutura que funciona para a interligação de situações cômicas: a espirituosidade põe em evidência aspectos político-sociais que podem ser considerados como forças motrizes da estrutura dramatúrgica. "Fo é essencialmente um animal político, que tem exercido influência decisiva em tentativas de unificar uma esquerda italiana fragmentada e conflituosa através do meio da sátira política." (Mitchell, 2000 , p. XVII) No teatro de Fo, não há um discurso doutrinário já que não se apresentam soluções. Há, ao invés disso, uma orientação marxista de vertente gramsciana, isto é, uma provocação no sentido da urgência de se construir uma cultura da classe trabalhadora, pois na estrutura cultural de uma sociedade é que estão embutidas práticas naturalizadas de dominação e subserviência (D'arcens, 2012). Essa dinâmica criadora está presente na maior parte dos espetáculos da carreira de Fo e certamente emerge em todos de 1968 para cá. Na próxima sessão, examino os princípios ordenadores constitutivos de teatro de Fo através de um de seus últimos espetáculos.

\section{Um modelo Genial Ao Alcance De Todos}

\section{A palestra-espetáculo Picasso Desnudo} pode ser considerada um ponto culminante da Companhia Teatral Fo Rame por algumas razões cruciais: por ser um trabalho maduro da dupla, que, em 2012, completou sessenta anos de casamento; por ser o último espetáculo com a parceria de Rame, falecida no ano seguinte; e finalmente, por ser um espetáculo pontuado de referências desconstrutivas quanto à dinâmica criadora do teatro de Fo.

Com a iluminação do espetáculo feita com

\footnotetext{
${ }^{2}$ Cumpre notar que os dialetos da Itália, país cuja unificação só se dá no século XIX, eram as línguas francas de cada províncida, de cada cidade, de cada povoado. Somente com a invenção e a crescente popularização do rádio, é que a língua italiana, derivada do dialeto toscano, passa ser língua oficial.
} 
luz geral acesa, telas evocativas da obra de Picasso projetadas num telão ao fundo do palco e o playback de canções com sonoridade espanhola na voz de Fo, o público esperava o começo do espetáculo. Fo entrou com roupa casual: camisa para fora da calça. Cumprimentou o público, deixando claro seu agradecimento por ter casa lotada numa sala com capacidade para 1.500 pessoas. A ausência de figurino e a movimentação da entrada de Fo, com interação direta com a plateia, signos de informalidade, estabeleciam como convenções da cena a preponderância da realidade sobre a ilusão. Desde o início, Fo dava a entender ao público que não havia quarta parede e que, portanto, a cena que se abria não era teatro convencional de cunho realista. Ao contrário, a personalidade do ator-dramaturgo-diretor se deslocaria aqui e ali de modo que personagens eventualmente surgissem sem nenhum outro recurso além do gestual e da modulação da fala e das imagens projetadas numa tela no fundo do palco. Em seguida, enquanto se sentou em uma cadeira alta, posicionando uma das pernas quase esticada, pronta a se levantar repentinamente, Fo disse vibrantemente:

$\mathrm{Na}$ internet, no início de agosto, foi divulgado que, em Milão, em meados de setembro, haveria, uma mostra de Picasso proveniente do Museu Nacional Picasso, em Paris. Não se passou uma semana, e nos escritórios do Palácio Real, onde está a mostra... começou hoje pela manhã... bem, venderam a avalanche, a maravilha de 150.000 ingressos para a mostra! É um fato realmente excepcional! $\mathrm{E}$ ainda naqueles dias, aconteceu outro fato imprevisível no que me diz respeito: me foi proposta pela Secretaria de Cultura de Milão comentar as mais de duzentas obras expostas na mostra e de comentar a história, a genialidade desse personagem irrepetível que é Picasso. Escrevemos o texto. Já tínhamos experimentado o espetáculo na Emília Romanha, mas, de repente, surgiu uma dúvida. Embora nós, como companhia teatral, estejamos trabalhando no âmbito da mostra em prol da exposição, alguém se lembrou que a agência que cobra os direitos autorais para os herdeiros de Picasso, numa situação análoga, bloqueou a produção e, num caso, chegou mesmo a suspender um filme sobre o artista que já [havia] sido rodado, com a demanda que os direitos autorais das obras reproduzidas no filme fossem pagos. Notem bem: no nosso caso, fazemos uma verdadeira lição, o espetáculo... o ingresso - vocês sabem - é gratuito, não temos nenhuma vantagem econômica. É como se, de repente, numa escola de arte ou numa universidade, ao final de uma série lições sobre um artista de grande valor, um pintor, um músico... se apresentassem ali os encarregados da sociedade dos autores para receberem uma ajuda devida. É paradoxal. É uma coisa que não existe. Não existe na verdade. Portanto, para não entrarmos em polêmicas e sobretudo para não sermos obrigados (Levantou-se da cadeira e se deslocou em direção ao público.) a desembolsar cifras exorbitantes de direitos, que nos deixariam de joelhos, tivemos uma ideia... permitam-nos... (Abriu os braços, deu uma gargalhada discreta e sorriu.) genial! Na tela, não projetaremos (Vira-se para o fundo do palco e aponta para a tela.) obras originais de Picasso mas somente produções reelaboradas por nós, a bem dizer, falsos, falsos originais - fique entendido - como aquele! (Gargalhou com mais entusiasmo do que na primeira vez.) E a coisa exraordinária é essa: com relação aos falsos, ninguém pode cobrar coisa alguma. Estou certo que, no além, neste momento, Picasso está rindo como um louco! (GargaIhou com mais entusiasmo ainda. $O$ público aplaudiu.) Bem, retornemos à mostra, (Começou a retonar à cadeira e se sentou novamente.) à lição sobre Picasso Nu.

Essa fala contextualizava a gênese, a importância e a existência potencialmente ameaçada do próprio evento espetacular em questão, revelando o conflito resultante de uma 
superestrutura cultural na qual as elites procuram manter sua hegemonia, enquanto as classes subalternas são induzidas à inação pública- sem o perceberem muitas das vezes. Esse conflito ideológico é bastante palpável e envolve a própria plateia como personagem -participante na medida em que a plateia se beneficia da palestra-espetáculo como um serviço público e funciona como um interlocutor ativo à medida que intervinha através de risos e aplausos quando bem entendia. Portanto, desde sua liminaridade, o espetáculo expunha, metalinguisticamente, a questão fundamental do teatro de Fo, isto é, a da importância da agência - de modo que os menos atentos à questão se conscientizassem da possibilidade de constitui-la, pois agência depende de iniciativa e de continuidade dessa iniciativa.

O primeiro conflito de Picasso $\mathrm{Nu}$ foi a voracidade capitalista em sua incapacidade de distinguir os limites do bom senso. Fo deu a entender aos espectadores que, se a equipe (e possivelmente ele mesmo por ser um pintor e o próprio autor das obras projetadas na tela) não tivesse concebido a ideia de recriar os quadros de Picasso, haveria o risco de inviabilidade do espetáculo. A possível ameaça, entretanto, foi derrotada, antes mesmo de ter a chance de se manifestar concretamente, por obra da engenhosidade do oprimido ativista - como numa ação de Arlequim, o oprimido esperto o bastante para se safar de situações desfavoráveis, não à toa personagem pintado por Picasso em mais de trezentos quadros e interpretado nesse espetáculo por Fo. A dialética do senhor e do escravo encontrou aqui uma materialização eloquente na medida em que a confluência ator-autor-personagem anulava uma potencial ofensiva do opressor implícito no sistema através do riso, tanto do próprio riso de Fo quanto do riso do público. Consistentemente, em modos análogos, o teatro de Fo extrapola o conflito inerente ao texto, ao universo dos personagens do drama, e o faz pertencer aos espectadores de modo imediato, direto. Uma vez superado o problema absurdo dos direitos autorais, a vitória é de Fo, do público, da cultura teatral, da Secretaria de Cultura de Milão e do próprio Picasso, que, segundo o relato de Fo, opor-se-ia a uma situação de exploração excessiva, como essa.

Depois de triunfar espetacularmente sobre a burocracia e a ganância da SIAE (Sociedade Italiana dos Autores e Editores) e dos herdeiros de Picasso, Fo retornou à sua cadeira, sentou-se relaxadamente com os dois pés no tablado - pois agora, depois de ter tirado do caminho uma questão visceralmente desagradável, ele podia se dar ao luxo de relaxar. Então, começou a contar a história do protagonista da noite. Mencionou que Picasso se referia ao privilégio de ter sido filho de um pintor, Don José, professor da Escola de Belas Artes de Málaga, o qual, ao constatar o talento extraordinário do filho assim que viu um quadro que o menino tinha pintado a partir de um tema por ele proposto, entrou em crise de espanto. No dia seguinte, Don José deu todos os seus materiais de pintura ao filho e disse que jamais voltaria a pintar, tendo realmente cumprido a promessa. Fo interpretou a voz de Don José em estado de estupefação e retornou à voz de Picasso, mais serena, enquanto na tela ao fundo, eram projetadas imagens pintadas por Fo que ilustravam o discurso:

(Com a voz serena.) Aprendi a amar os grandes pintores antigos, especialmente aqueles do meu país: El Greco, Velasquez, Goya, esse famoso pela Maja, a Maja Vestida e a Maja Nua. 
(Modulando a voz para o entusiasmo a fim de marcar a diferença entre a sua própria fala e a de Picasso e começa a caminhar com decisão pelo palco.) A propósito, este maravilhoso retrato duplo de mulher que vemos aqui projetado... repentinamente, me perguntei: mas por que, depois de ter pintado a sua amada com ternura deitada com um vestido refinado sobre um divã, (. . . ) Goya a pôs nua na mesma atitude, mostrando-a nua a toda a cidade? $\mathrm{E}$ simples: Francisco amava essa criatura mais do que qualquer outra no mundo. Portanto, a mostrou nua não porque quisesse vingar-se e puni-la por ter sido traído e abandonado, (Faz um passo marcadamente mais ligeiro e amplo do que os que vinha fazendo antes.) justamente como pensam estupidamente certos comentadores eruditos. Mas para lhe dar um grande presente: despi-la de modo que todos pudessem admirá-la na sua integridade e para que pudessem dar-se conta inteiramente de quanto fosse impossível não perder a cabeça por ela. (Com um sorriso largo.) Bem... não acontece todos os dias de se encontrar Vênus em pessoa.

No trecho acima, que já faz parte do corpo do texto propriamente dito do espetáculo, há evidências de que Fo improvisou em suas falas: a linguagem tem marcadores inequívocos de um discurso que vai se formando espontanemante a partir de conhecimento consolidado, da investigação narrativa da qual ele está seguro, como um professor proferindo uma aula na qual uma sequência de slides ou de tecnologia análoga lhe servem de orientação para a fluência do discurso sem amparo de leitura alguma. Então, a memorização do roteiro não é a memorização de palavra por palavra. O discurso memorizado é um percurso semântico dominado inteiramente desde a origem, isto é, das fontes consultadas pelo ator-autor e não necessita do rigor formal da literalidade.
Quanto ao fato do trecho acima ser uma digressão, o é apenas aparentemente. Na verdade, Fo estava abrindo espaço para um tema que lhe é demasiadamente caro: desmontar o preconceito cristão do sexo pecaminoso, que leva inescapavelmente à culpa. A Igreja Católica - e quando se remete à Igreja Católica dentro da Itália, deve-se ter em mente uma proximidade muito maior do Vaticano, ou seja, de uma interseção patente entre religião, cultura, corpo e estado mais do que em qualquer outro país do mundo. Também não nos esqueçamos de que a Igreja Católica foi responsável por um número considerável entre as dezenas de processos judiciais pelos quais Fo foi indiciado, sobretudo os processos judiciais motivados por alegação de blasfêmia.

Na sequência, Fo justificou, com mais direcionamento, a digressão num nível de consistência formal no espetáculo:

(Aqui a fala é de Fo.) Ah, a propósito de obras sublimes: Pablo suscitava um conceito paradoxal: que a mediocridade de um pintor pode ser medida como se aproprie da obra de um grande artista. (Aqui começa a fala de Picasso, que segue num crescendo de entusiasmo.) Quase sempre, o pintor em questão declara não copiar a obra do grande mestre mas de se inspirar nele. É aí que está a banalidade burra! $\mathrm{Na}$ verdade, um pintor de alta qualidade - e me desculpem se me permito incluir-me entre eles - jamais se limita a traduzir as emoções que lhe provocam um grande mestre mas pega toda e inteira a sua pintura: cores, formas, linguagem e carrega a moldura também se descobre que é valiosa. (. . . ) Eu, sempre com esforço, me fiz ser apreciado. Estudei, aprendi todas as técnicas: da têmpera à pintura a óleo, à gravura, à escultura, frequentei pintores de grande talento, procurei fazer com que fosse minha a linguagem deles. Depois, no fim, realizei a mais importante das minhas ações: inventei Picasso! (Risos baixos na plateia. 
Fo retoma sua própria voz.) Aquele grupo ali entendeu [a piada]! Quinze entenderam! (Os risos, embora ainda baixos, se multiplicam consideravelmente.)

Fo atacou o trecho acima com uma modulação de voz que ia desde o absolutamente incidental, conforme prometia a expressão introdutória da nova sessão do discurso - "a propósito" - e o encaminhou num crescendo de assertividade até, depois de uma pausa expressiva, vibrar com sobriedade a respeito da conclusão de Picasso. Aqui, o desnudamento de Picasso coincidiu, por deslocamento, com o desnudamento do próprio Fo. Ao utilizar a declaração de Picasso, obviamente apropriada e esperada dado o tema do espetáculo, Fo fazia uma afirmação com respeito à sua própria formação como dramaturgo-ator-diretor. Essa afirmação também poderia ser lida, com uma mínima margem de erro, creio eu, de acordo com as evidências, como um ataque a um comportamento erudito oco e desprovido de rigor e de vigor mas desavergonhadamente em voga desde sempre e gozando dos tributos da cultura oficial de modo a perpetuar um sistema de classes que necessariamente estabelece uma homologia entre valor artístico e classe dominante, refinada. Como disse mais adiante, citando dessa vez Rafael, outro modelo de Picasso, "insultem o poder até que se esfolem", uma palavra de ordem que incitava à radicalidade e à luta incansável contra os desmandos da cultura oficial.

Visto que a cultura oficial também conta com alguns talentos de alto quilate, Fo evocou o caminho percorrido por outro pintor espanhol contemporâneo de Picasso:

Da Espanha, alguns franquistas tentavam convencer o mestre [Picasso] a retornar à Espanha. (. . .) Alguns aceitaram, como, por exemplo, Dali, que aceitou a oferta e obteve grandes honras e proteção do regime, o que mostra que arte e coerência civil e não convivem necessariamente no mesmo homem.

Mais uma vez aplaudido em cena aberta, Fo colocou em evidência, dessa vez por contraste, a consciência política que permeava a obra de Picasso, autor, por exemplo, além da famosa Guernica, também comentada na palestra-espetáculo, de várias ilustrações de pombas da paz que, conforme observou Fo recorrendo à evidência pictórica, não eram representações da paz entendida como conformismo, mas representações de que a paz frequentemente é atingida através da luta.

Fo mostrava, assim, como o fez com tantas outras anedotas e projeções dos "falsos originais de Picasso", como a arte pode ser inerente à dimensão política da vida, superando a dicotomia entre forma e conteúdo, outra invenção manipulatória da cultura oficial. Coerentemente, Picasso Desnudo não foi um trabaIho destinado exclusivamente à promoção de um conteúdo cultural mas cumpriu tal função tanto através da diversão, que envolve inescapavelmente o corpo, quanto da difusão da consciência de luta contra a opressão, transversalmente presente numa linhagem de artistas da magnitude dos contadores de histórias de fama modesta e de eloquência picante, dos atores da Commedia dell'Arte, de Ruzzante, de Rafael, de Goya e de Picasso. Germinando dessa raiz, o teatro de Fo tem se mantido por se colocar parâmetros dos quais não pode abrir mão: principalmente o de que entretimento de alta qualidade pode ser político e o de que o político não precisa ser e não deve ser chato.

Melo // O Teatro de Dario Fo: desnudando fo em picasso nu 
BAKHTIN, Mikhail. Discourse in the Novel. In: BAKHTIN, Mikhail The Dialogic Imagination: Four Essays. Edição de Michael Holquist. Tradução de Caryl Emerson e Michael Holquist. Austin: University of Texas Press, 1985. Pp. 259-422.

BEHAN, Tom. Dario Fo: Revolutionary Theatre. London: Pluto Press, 2000.

D'ARCENS, Louise. Dario Fo's Mistero Buffo and the Left Modernist. In: ASHTON, Gail; KLINE, Daniel T Medieval Afterlives in Popular Culture. New York: Palgrave Macmillan, 2012. pp. 57-70.

FO, Dario; RAME, Franca. Picasso Desnudo. Palestra-espetáculo, com direção de video de Ben Fatto, filmado no Teatro dal Verme, Milão, em 19/12/2012. Disponível em: http://www. rai5.rai.it/articoli/picasso-desnudo/29688/default.aspx

MITCHELL, Tony. Dario Fo: People's Court Jester. London: Bloombsbury, 2000.

1997 Nobel Prize for Literature Press Release, disponível em:http://www.nobelprize.org/ nobel_prizes/literature/laureates/1997/press. $\mathrm{html}$

SCUDERI, Antonio. Dario Fo and oral tradition: creating a thematic context. Oral Tradition, 15/1 (2000). 